\title{
Em gênero e sexualidade aprende-se pela repetição com diferença: cenas escolares
}

\author{
Yara de Paula Picchetti \\ Fernando Seffner \\ Universidade Federal do Rio Grande do Sul
}

\section{Resumo}

O artigo traz cenas ocorridas no ambiente escolar em que a heteronormatividade é propagada não só a partir da marginalização das expressões de gênero e sexualidade não-hegemônicas, mas principalmente pela minuciosa atuação da norma que induz pressupor a heterossexualidade como a sexualidade verdadeira. Há um conjunto sutil de pedagogias que nos convida a repetir a norma, acenando com benefícios de inserção social. Mas há contingências, indagações, interpelações, confrontos que nos fazem repetir com diferenças o que a norma prescreve, e este é o espaço da educação, sempre tensionada pela repetição da norma com diferenças, fruto dos novos contextos e das demandas das culturas juvenis.

Palavras-chave: Heteronormatividade. Norma. Diferença. Repetição. 


\section{Abstract}

The article presents scenes that occurred in the school environment in which heteronormativity is propagated not only by the marginalization of non-hegemonic expressions of gender and sexuality, but mainly by the meticulous performance of the norm that induces heterosexuality to be assumed to be true sexuality. There is a subtle set of pedagogies that invites us to repeat the norm, waving with benefits of social insertion. But there are contingencies, inquiries, interpellations, confrontations that make us repeat with differences what the norm prescribes, and this is the space of education, always stressed by the repetition of the norm with differences, fruit of the new contexts and the demands of youth cultures.

Keywords: Heteronormativity. Norm. Difference. Repetition.

\section{Resumen}

El artículo presenta escenas que se dieron en el entorno escolar en el que la heteronormatividad se propaga no sólo de la marginación de las expresiones de género y la sexualidad no hegemónica, pero principalmente por el meticuloso desempeño de la norma que induce a la heterosexualidad a ser considerada como verdadera sexualidad. Hay un conjunto sutil de las pedagogías que nos invita a repetir la norma, agitando beneficios de la inclusión social. Pero hay contingencias, preguntas, interpelaciones, enfrentamientos que nos hacen repetir con diferencias la norma prescribe, y este es el área de la educación, siempre tensada mediante la repetición de la norma con las diferencias, el resultado de los nuevos contextos y demandas de la cultura juvenil.

Palabras clave: Heteronormatividad. Norma. Diferencia. Repetición. 


\section{Abstrait}

L'article présente des scènes qui se sont produites dans le milieu scolaire dans lequel l'hétéronormativité se propage non seulement par la marginalisation des expressions de genre et la sexualité non hégémonique, mais surtout par la performance méticuleuse de la norme qui fait supposer que l'hétérosexualité est la vraie sexualité. Il y a un ensemble subtil de pédagogies qui nous invite à répéter la norme, en agitant les avantages de l'insertion sociale. Mais il y a des contingences, des questions, des interpellations, des confrontations qui nous font répéter avec des différences ce que la norme prescrit, et c'est l'espace de l'éducation, toujours tendue en répétant la norme avec les différences, le résultat de nouveaux contextes et les exigences de la culture des jeunes.

Mots-clés: Hétéronormativité. Norme. La différence. Répétition.

\section{Heteronormatividade, norma, heterossexualidade e ambiente escolar}

O que cabe e o que não cabe à escola tratar em termos de gênero e sexualidade, repartindo ou não suas tarefas com a família e com outras agências educativas como as instituições religiosas, é questão polêmica e antiga. Na esteira do que já tratamos em trabalhos anteriores1, enfatizamos aqui nossa posição teórica e política sobre o tema: a escola pública, laica e republicana tem o dever de abordar essas questões, propiciando um ambiente de acolhimento e respeito às diferentes opiniões. Essa é uma tarefa intrínseca do espaço público republicano, e a escola é o aprendizado para a vida no espaço público. Ela também se vincula à tarefa de ensinamento científico da escola, e aqui se conjugam as duas dimensões básicas da educação pública: alfabetização científica e formação do cidadão republicano. O espaço público é marcado pela produção de sujeitos capazes de conviver e negociar diferenças e, nesse campo se "[...] enfatiza o papel da escola pública brasileira na construção de indivíduos que valorizem esta possibilidade, resgatando um elemento fundamental da noção histórica de 'modus vivendi': capacidade de construir acordos entre 
indivíduos e grupos cujas opiniões diferem"2. Sabemos que as opiniões sobre gênero e sexualidade experimentam fortes oposições e dissensos e, quando nos referimos a estabelecer uma dimensão política nestes temas, pensamos a política "[...] como estratégia de produção do bem comum, fortemente conectada com as noções de articulação - dispositivos que promovem a possibilidade de movimento - e com a compreensão de que a escola está centralmente envolvida com as pedagogias da sexualidade e de gênero, que se manifestam dentro e fora da sala de aula, auxiliando a produzir sujeitos marcados por gênero e sexualidade"3. Nunca é demais lembrar que as sociedades ocidentais contemporâneas são em geral democracias fortemente pluralistas, ou seja, compostas por agrupamentos de sujeitos que se associam por diferentes marcadores de identidade, e o consenso para a vida em comum não será atingido com posturas fundamentalistas, que não admitam o diálogo e a negociação de pontos de vista.

Iniciamos a abordagem dos conceitos centrais do texto com afirmações comuns, de fora da escola, pela simples razão de que elas, cedo ou tarde, são motivo de debate em sala de aula. Não há muros capazes de isolar a escola pública brasileira do seu entorno social, e semelhante situação inclusive não é desejável, pois a escola, voltamos a frisar, se ocupa da alfabetização científica, mas também da formação do cidadão. Nesse sentido, trazemos neste artigo cenas que ocorreram no espaço escolar, mas não necessariamente são específicas deste contexto. Compreendendo que existe continuidade entre a escola e a cultura em que se situa, as situações descritas têm ressonância com o que está fora dos muros escolares. Por outro lado, a escola não deixa de ser um lugar privilegiado para reflexão e debate de temas ligados aos direitos humanos e à diversidade, como é o caso das normalizações vigentes no campo da sexualidade e gênero.

Algumas falas servem para analisar um tipo de vínculo comum atualmente: o condicionamento do respeito a uma adequação normativa do outro, como construções que já viraram jargão satírico em redes sociais e nas conversas pessoais, representadas principalmente pela frase 'Eu não tenho preconceito, mas.... A conjunção adversativa torna o discurso contraditório, fazendo com que a frase do suposto não preconceituoso se torne motivo de piada. No campo da sexualidade, outras ideias comuns são 'Tudo

2

SEFFNER, 2015, p.81.

3

"Reiterações e Transgressões à Heteronormatividade na Escola em Tempos de Educação para Diversidade", de autoria de Yara de Paula Picchetti, disponível em http://www.lume.ufrgs.br/handle/10183/106452, acesso em mai. 2015. Uma segunda fonte de dados e análises deriva do projeto de pesquisa "Processos culturais e pedagógicos de produção, manutenção e modificação das masculinidades: Articulando duas direções de investigação", coordenado por Fernando Seffner, informações disponíveis em seu currículo online. 
bem em ser gay ou lésbica, desde que não manifeste seus afetos em público' ou 'Pode ser gay, só não pode ser afeminado'. Há o reconhecimento de uma identidade, porém seguido de uma regra que reforça um padrão vigente, que reitera a norma. Algumas vezes essa reiteração da norma é menos explícita, o que a torna poderosa produtora de verdades, pois que a norma opera fortemente em cima de silêncios e não ditos, em cima de questões que não se podem perguntar e nem se podem falar abertamente, e isso vale para os temas de gênero e sexualidade com muita ênfase.

A garantia de direitos humanos para todos e todas envolve complexas negociações com a norma e com os modos de ser "normal". Os movimentos sociais progressistas e em sintonia com o respeito ao pluralismo democrático se tornaram expoentes no Brasil nas últimas décadas e fizeram proliferar legítimas reivindicações em diversos setores, como cotas no vestibular a partir de recortes étnico-raciais e socioeconômicos; extensão do casamento civil a casais do mesmo sexo; garantia de cirurgia de mudança de sexo pelo Sistema Único de Saúde a transexuais; garantia de respeito com o uso do nome social em sintonia com o gênero pretendido, apenas para citar alguns exemplos. Estas conquistas são essenciais para viabilizar uma vida digna para grupos historicamente discriminados. Mas são lutas que precisam também alimentar a inquietação necessária para mudarmos o funcionamento da norma. Nesses exemplos, há que se cuidar para não perder força a luta que discute a própria forma de ingresso nas Universidades, o questionamento do papel da instituição do casamento e da monogamia em nossa sociedade e sua regulação pelo estado e o modo como os gêneros são construídos de forma binária e rígida em nossa cultura. Foucault narra a história da sexualidade sob a ótica da produção de verdade sobre o sexo e das relações poder-saber envolvidas. Para o autor, a partir do século XVIII, as sociedades ocidentais trataram de colocar o sexo em discurso, tornando-o alvo de intervenção e objeto de conhecimento. O sexo tem sido incitado e investido pelo poder-saber no âmbito de diversas instâncias, configurando, assim, o dispositivo da sexualidade. Nessa malha poder-saber, o casal monogâmico heterossexual torna-se cada vez mais legítimo e, ao mesmo tempo, cada vez menos se fala a seu respeito, tornando a heterossexualidade instituída de efeito de verdade (Foucault, 2009). Desse modo, a heterossexualidade é tida como uma verdade sobre a essência da sexualidade e da identidade dos sujeitos. E essa é uma verdade que não precisa se explicitar a todo o momento enquanto tal, pois é legitimada por diversos meios e assim naturalizada. A heterossexualidade tornou-se a norma.

Desse modo, no dispositivo da sexualidade movimenta-se uma complexa rede em função da heteronormatividade, mesmo que a manutenção da hegemonia heterossexual não seja sua estratégia única e global. As construções normativas são pressupostos silenciosamente compartilhados e compulsoriamente assimilados que fazem funcionar expectativas sociais, mas, pressupostos estes que não se realizam a partir de apropriações de elementos culturais acabados, e sim como efeitos ativamente produzidos pelos sujeitos na linguagem e na cultura. Por meio 
de pedagogias da sexualidade e de gênero, saberes formais e informais difundem-se de modo a ensinar modos de ser e viver no que se refere à sexualidade e às relações de gênero, propagando normas. Através dessas pedagogias, múltiplas esferas sociais exercem o disciplinamento de corpos e a condução de condutas de forma "muitas vezes sutil, discreta, contínua, mas, quase sempre, eficiente e duradoura" (Louro, 2000, p. 17), pois também contam com o aprendizado de autodisciplinamento e autogoverno que os sujeitos passam a exercer sobre si mesmos ao longo da vida. Principalmente a fim de garantir as normas sociais de gênero, uma incisiva disciplina exercida por diversas instâncias, como meios midiáticos, instituições, figuras de autoridade e também por pares, atua sobre os sujeitos apreendendo os detalhes de seus gestos, incitando o treinamento de condutas esperadas e promovendo sanções aos que escapam às normas de sexualidade e gênero engendradas na cultura.

O sujeito é constituído na norma, é um efeito dela. Geralmente a manutenção normativa é desempenhada pelos sujeitos com grande adesão e alguma motivação, pois manter-se normalizado promete felicidade, admiração e saúde. Porém, ao efetuarse a partir da norma, este também pode dela distanciar-se. Assim, dispositivos de aprendizado, como as pedagogias da sexualidade e de gênero, não são determinantes dos modos de agir dos sujeitos. A existência dessas pedagogias não leva a um fim determinado, pois, ao passo que atuam mostrando direções e insistindo em saberes e posições, permitem ao indivíduo recusar, aderir parcialmente, subverter, modificar. Portanto, é possível tanto a reiteração quanto a transgressão à norma e à heteronormatividade, o que estamos aqui também denominando de repetição e repetição com diferença.

A heteronormatividade é o nome que têm recebido os arranjos e efeitos da atuação da norma no campo da sexualidade. O termo foi cunhado por Michael Warner (1993) e designa um conjunto de disposições como discursos, valores e práticas por meio das quais a heterossexualidade é instituída e vivenciada como única possibilidade natural e legítima de expressão. A heteronormatividade refere-se à rede que atravessa o dispositivo da sexualidade, produzindo processos de normalização que constituem a heterossexualidade enquanto hegemônica, conferindo-Ihe naturalidade. É uma ordem social, histórica, política e cultural que, juntamente com as relações de gênero, integra o dispositivo da sexualidade, produzindo compulsoriedade e pressuposição de heterossexualidade, constituindo subjetividades e conduzindo não somente desejos e práticas sexuais, mas também modos de vida e formas de organização social e institucional. Porque é empreendido de maneira continuada e constante pelas mais diversas instâncias sociais, o processo de reiteração de heterossexualidade adquire consistência e invisibilidade, confundindo-se com o fundamento das coisas, como se fizesse parte do funcionamento natural do mundo (Louro, 2009). Assim, no campo da sexualidade, muitas vezes a norma atua de forma sutil e minuciosa, produzindo seu efeito de naturalidade. 
Muitas são as condições que possibilitaram a heteronormatividade. Dentre estas, podemos citar o pensamento dicotômico típico da modernidade, a forma como a sexualidade e principalmente a homossexualidade foi investida pela psiquiatria desde o século XIX e o peso que as ciências da natureza e a estatística têm em nossa cultura, dando enfoque ao corpo a partir de uma concepção de sexualidade essencialista, ligada à reprodução e a outros processos relacionados à gestão da vida da população, e estabelecendo poderosas conexões entre a média e a norma. Muitos estudos que partem de uma concepção construcionista da sexualidade discutem que esse status da heterossexualidade é sustentado principalmente pela suposição de coerência entre sexo-gênero-desejo (Butler, 2003), que prevê combinações lineares e fixas no campo da sexualidade.

A lógica binária está inscrita na tradição ocidental moderna. Assim como outros dualismos (bom/mau, certo/errado, limpo/sujo), sexualidade e relações de gênero estão organizadas por essa lógica em nossa cultura, produzindo processos de diferenciação e hierarquização, portanto, implicadas em relações de poder. Os dualismos no campo da sexualidade e do gênero produzem uma estreita articulação entre estes. A sustentação do binômio homossexualidade/heterossexualidade depende da divisão binária do gênero na medida em que um relacionamento afetivo-sexual é identificado como homossexual apenas se os sujeitos envolvidos são reconhecidos como do mesmo gênero e, no que se refere à heterossexualidade, se são reconhecidos como do gênero oposto. Da mesma forma, a divisão binária feminino/masculino é garantida pelo binômio homossexualidade/heterossexualidade. Na medida em que descumprimos os scripts sociais de gênero estabelecidos (Gagnon, 2006), entram em ação processos de adequação à heterossexualidade. Nesse quesito, é possível observar, então, uma valoração que hierarquiza homossexualidade e heterossexualidade. Formas hegemônicas de masculinidade e feminilidade são associadas à heterossexualidade em nossa cultura, operando-se, portanto, um padrão heteronormativo.

Assim, a adesão a padrões sociais de gênero torna os corpos heterossexualizados, reconhecíveis ao outro enquanto congruentes à ordem social heteronormativa. Mas, corpos e subjetividades também se constituem de modo a 'escapar' em alguns aspectos a delimitações impostas pelos padrões de gênero e sexualidade. Quando isso acontece, esses sujeitos acabam por ocupar um lugar socialmente deslegitimado e, não raro, hostilizado, já que expressam 'o que não se deve ser'. Porém, ao mesmo tempo também trazem consigo a potencialidade de borrar as fronteiras cotidianamente restabelecidas por operações normativas repetitivas. A explicitação do entrelaçamento entre questões de gênero e sexualidade permite visualizar que a regulação de um remete ao controle do outro e vice-versa, e que essa relação sustenta a heteronormatividade. Suas expressões não se restringem a relações interpessoais e cumprimento de papéis sociais de gênero. Ambos, sexualidade e relações de gênero, estabelecem divisões sociais hierárquicas que são difundidas pelo tecido social e incorporadas por instituições. Bem como a oposição feminino/ 
masculino, a oposição homossexual/heterossexual "organiza as práticas sociais, o conhecimento e as relações entre os sujeitos" (Louro, 2001, p. 549).

Gayle Rubin (1993, p. 12) chama a atenção para a intrínseca relação entre gênero e sexualidade quando afirma que gênero "[...] supõe que o desejo sexual seja direcionado ao outro sexo". A partir disso, a autora concebe a heterossexualidade obrigatória originada no que denominou sistema sexo/gênero como mecanismo de opressão, e propõe a eliminação das sexualidades obrigatórias, imaginando uma sociedade andrógina. Em "Heterossexualidade compulsória e existência lésbica", Adrienne Rich (2010, p. 35) traça uma crítica à concepção naturalizada de mulher como heterossexual. O termo cunhado, "heterossexualidade compulsória", expressa, além da pressuposição, também uma obrigatoriedade de heterossexualidade, "[...] algo que tem sido imposto, administrado, organizado, propagandeado e mantido por força".

Heterossexualidade obrigatória e heterossexualidade compulsória podem ser consideradas como conceitos precursores do conceito de heteronormatividade. É possível compreendê-los pela lógica segundo a qual a norma heterossexual atua no sentido de manter a maioria da população dentro das fronteiras da heterossexualidade, sancionando esse modo de ser e estabelecendo hierarquias. A partir disso, toma-se a heteronormatividade como os modos pelos quais a norma heterossexual obrigatória e compulsória é constituída e funciona na rede das relações de gênero. Expandindose pelo tecido social, ela toma a forma hegemônica. Refere-se à atuação da norma heterossexual e seus desdobramentos, produzida em meio a relações de poder e funcionando com um conjunto de estratégias. Para Miskolci,

a heteronormatividade é um conjunto de prescrições que fundamenta processos sociais de regulação e controle, até mesmo para aqueles que não se relacionam com pessoas do sexo oposto. Assim, ela não se refere apenas aos sujeitos legítimos e normalizados, mas é uma denominação contemporânea para o dispositivo histórico da sexualidade que evidencia seu objetivo: formar todos para serem heterossexuais ou organizarem suas vidas a partir do modelo supostamente coerente, superior e 'natural' da heterossexualidade. (Miskolci, 2009, p.156-157)

Para exemplificar o funcionamento da heterossexualidade como privilégio, Eve Sedgwick (2007) utiliza a metáfora do armário, na qual o armário representa o regime de controle da sexualidade que mantém a divisão binária heterossexual/homossexual e fora/dentro ou público/privado, em que os sujeitos homossexuais são expostos a contradições e constantes demandas. Permanecer no armário, ou seja, não 'se assumir', pode trazer uma série de restrições de vivências, com impactos emocionais e sociais. Por outro lado, 'sair do armário' pode ser considerado uma postura política, mas é provável que o sujeito seja enclausurado em sua identidade, ou seja, torne-se reconhecido apenas a partir desta, ocupando posição inferior na hierarquia social e tendo todas as dimensões da sua vida julgadas a partir de um vínculo identitário exclusivo, por exemplo, ser gay. Além de seu custo individual, a autora enfatiza que 
o ato de sair do armário não implode o binarismo inerente à heteronormatividade que afeta, inclusive, a vida de heterossexuais.

Os preconceitos de sexualidade e gênero estão relacionados à heteronormatividade na medida em que é aos que fogem a esta ordem social vigente que se dirigem injúrias e discriminações. Algumas vezes essas ações adquirem um caráter mais explícito, envolvendo agressões físicas e até mesmo a morte como forma de delimitação de identidades e modos de vida que são consideradas viáveis e aceitáveis segundo o padrão vigente. Em outros momentos, a norma é retomada mais sutilmente, de modo quase imperceptível, mas de maneira a suportar posteriormente meios mais violentos ou extremos de perpetuação. São a estas formas mais sutis de propagação da norma que vamos nos deter neste trabalho.

Segundo Ewald (2000), Foucault entende a norma como veículo do poder e ligada a uma tecnologia positiva de intervenção. Assim, o que a caracteriza não é o uso da força, mas uma lógica, uma economia, uma maneira de o poder refletir as suas estratégias e definir os seus objetivos. Para pensar sobre os mais diversos fenômenos sociais nas sociedades ocidentais modernas, Foucault sugere uma analítica das condições do exercício de poder e da produção de efeitos de verdade. É um trabalho meticuloso, atento ao pormenor, em que a atenção esteja conduzida aos detalhes, às ninharias, ao grão do poder. É dessa forma que temos procurado conduzir nossas pesquisas, percebendo as sutilezas da atuação da norma no campo da sexualidade, permitindonos captá-la em algum nível e descrever as dinâmicas que opera por meio de relações de poder no dispositivo da sexualidade, constituindo a heteronormatividade.

Neste artigo, nos ateremos a uma das formas de legitimação da heterossexualidade na condição de verdade, que é a pressuposição de heterossexualidade, a qual iremos analisar a partir das cenas escritas com base em eventos vivenciados durante o trabalho etnográfico realizado em escolas públicas da cidade de Porto Alegre, no âmbito de dois projetos de pesquisa4. 


\section{Dos modos de se dispor a ver e perceber}

O desenvolvimento de uma metodologia na pesquisa pós-estruturalista é transversal ao empreendimento, perpassando todos os momentos, desde o planejamento até a análise. Durante o planejamento, a metodologia começa a se delinear na escolha do campo e na forma de aproximação dos pesquisadores ao seu objeto. Para o presente trabalho, escolhemos como espaço escolas e, como estratégia, a etnografia, uma forma de pesquisa que se desenvolveu na antropologia e está sendo largamente utilizada na pesquisa em educação desde a década de 1970 (André, 1995). Mesmo que estratégia metodológica e campo sejam tradicionais em pesquisas em educação, diferentes adaptações são necessárias a cada pesquisa, como propõe a própria etnografia, de acordo com as particularidades das relações estabelecidas, dos materiais que se apresentam disponíveis e das características do objeto.

Nossa proposta etnográfica inicial não apresentava técnicas, momentos e espaços bem estruturados, pois a ideia era aproveitar-se do fortuito suscitado na dinâmica da pesquisa dentro da escola. Durante um semestre, de duas a três vezes por semana, de posse do diário de campo, permitimo-nos flanar pelas escolas selecionadas e registrar cenas em que possivelmente a produção da norma estivesse em jogo. A inserção comportou espaços escolares múltiplos, como pátios, quadra, banheiros, refeitório, sala das professoras e salas de aula, acompanhados tanto em momentos de intenso movimento quanto em horas em que estavam quase vazios. Aceitamos nos deixar envolver nas interações que ali surgiram e ouvimos uma multiplicidade de vozes nos espaços, muitas vezes participando das interações. Aos poucos, aprendemos a focar nos encontros que pareciam mais produtivos para pesquisar a atuação da norma no campo da sexualidade.

Geralmente a norma não é nomeada, é apenas reiterada por meio de práticas sociais e discursos e em função de sua naturalização, quando nomeada, por vezes, pode adquirir caráter de obviedade, provocando reações. Assim, mais do que identificar e nomear a norma, visibilizando-a em sua obviedade, procuramos descrever e analisar os arranjos em que a norma atua e seus efeitos, explicitando sua complexidade. Desse modo, o que a princípio pode revelar uma obviedade, pode sempre ser uma raridade, o que circunda suas diferenças é a forma de olhar. O olhar para raridade é o que Fischer (2003) sugere como atitude metodológica em nossas pesquisas. Os fatos e as coisas ditas são raras na medida em que há um vazio em torno de si mesmas, que são suas possibilidades múltiplas e complexas, que cabe a quem pesquisa descrever minuciosamente.

Essa noção de olhar para os fatos e coisas ditas como raridades converge com a ideia de que a norma sempre está sujeita à possibilidade do imprevisto, do contingente. Embora carregue consigo a ideia de conservação e estabilidade, a norma permite brechas e rachaduras, ela vaza, tropeça, gagueja. Dessa forma, olhar 
para as interações escolares como acontecimentos raros também é se possibilitar apreender as normas carregadas por essas práticas em sua incompletude e instabilidade, ou seja, em sua raridade. Assim, durante o percurso das pesquisas que alimentam este artigo, procuramos perceber as normas do campo da sexualidade e do gênero que habitam as interações no interior da escola nas situações mais cotidianas e aparentemente banais, captando os discursos de verdade nos quais se inserem, descrevendo relações que estabelecem para firmarem sua existência, possibilidades de transgressões nas suas reiterações, readaptações que operam ao serem tensionadas e efeitos envolvidos em suas atuações, tentando colher o ínfimo e raro grão de poder.

Foi preciso exercitar o olhar ao enfrentar o desafio de pesquisar algo discreto, astucioso e naturalizado. Treinar o olhar para a norma e não para a diferença, como é costumeiro, além de evitar capturar-se por discursos de teor benemerente, que usualmente povoam espaços como o ambiente escolar. Durante as interações, estivemos atentos, provocamos situações, comparamos diálogos. Também 'criamos' durante a pesquisa, pois isso nos é permitido e até recomendado na pesquisa pósestruturalista. "Quando se formula um problema de pesquisa, inventa-se também um peculiar caminho para procurar, produzir e propor alternativas de resposta" (Costa, 2002, p. 9). E criamos também um modo de contar estas duas cenas produzidas a partir das interações com crianças do ensino fundamental durante os recreios. 


\section{Quando a ordem dos fatores altera o produto}

[Juliana e Ingrid estão no $2^{\circ}$ ano e têm entre 07 e 08 anos.]

As duas meninas passam por mim acompanhadas de Fabiana, que eu havia conhecido por meio delas no dia anterior. Cumprimentam-me rapidamente com 'Oi' e vão brincar em outro lugar do pátio. Depois de um tempo, Fabiana volta sozinha para falar comigo e me pergunta:

- Tu está estudando?

Explico o que estou fazendo.

- Ah, então é igual a estagiária - ela conclui, e em seguida me confessa: Eu não gosto da Juliana.

- Não gosta?

- Não.

- Por quê?

- Ela é chata, fica indo atrás das pessoas.

Continuamos conversando e Fabiana lista vários nomes de meninas que, segundo ela, são suas amigas na escola. Pergunto:

- Não tem nenhum menino?

- Tem - incluiu o nome de dois.

Em seguida, Ingrid chega para se inserir na conversa. Neste momento Fabiana está apontando para meninas que passam pelo pátio, enquanto fala:

- Gosto dela, daquela outra, da Maria ali...

Ingrid também quer participar:

- Eu gosto da Fulana, Beltrana, Cicrana (somente nome de meninas).

Peço confirmação:

- Ah é, você gosta delas?

Ela apenas me confirma:

- Gosto.

Cena produzida a partir de trecho do diário de campo

As meninas parecem se sentir mais amigas de outras meninas, ou pelo menos têm 
mais liberdade para se dizerem amigas do mesmo gênero que do gênero oposto, mesmo que haja indisposições entre elas. Mas o mais interessante desse trecho é que foi a partir dele que percebemos a atuação da norma por meio da pressuposição de heterossexualidade, constituindo seu arranjo em função da heteronormatividade. Mas onde? Como? Relemos o trecho e não encontramos. Pois bem, propositalmente dividimos a cena em dois trechos e invertemos a cronologia dos acontecimentos justamente para produzir este efeito na leitura. Lendo somente o trecho acima não é possível perceber a pressuposição de heterossexualidade, no entanto, foi por meio dele que percebemos a presença dessa forma de constituição da heteronormatividade. $\mathrm{Na}$ verdade, o trecho que acabamos de narrar ocorreu no dia posterior ao que se segue e seu encadeamento foi fundamental para essa nossa percepção da norma. Segue, então, o diálogo com Ingrid e Fabiana do dia anterior, também durante o recreio:

Ingrid havia acabado de me apresentar Fabiana. Estávamos começando a conversar. Manuel vem correndo e mexe com elas, dando uns cutucõezinhos. Isso faz parte da forma como eles 'se convidam' para brincar, e uma resposta mais calorosa também faz parte do jogo que se instaura. Na maior parte das vezes, a provocação parte de meninos para meninas ou vice-versa, sendo muito recorrente esta divisão por gênero. Ingrid reage com bastante agressividade, gritando brava com ele e o mandando ir embora. Instigada pela recorrência deste tipo de situação, pergunto:

- Você não gosta dele?

- Não.

- Por quê?

- Porque eu odeio ele.

- O que ele faz?

- Ele é muito bobo.

Fabiana, que está do lado dela, cochicha algo em seu ouvido. Seguiu-se um pequeno intervalo de silêncio e Ingrid percebe que eu havia ficado 'de fora'. Olha pra mim e me conta:

- Ela falou que antes gostava dele, mas agora não gosta mais. - Fez uma pausa de uns 2 segundos e emendou - Como amigo né!? - olhando para mim e confirmando se eu havia entendido e acreditado que Manuel havia sido apenas um amigo para Fabiana.

Em poucos segundos, Manuel volta com as provocações e desta vez elas 'aceitam o convite' e saem correndo atrás dele.

Cena produzida a partir de trecho do diário de campo 
Enquanto no primeiro trecho o verbo 'gostar' veicula o significado suposto de amizade (completamente compreensível por todas as pessoas que estão na cena, sem precisar de explicações adicionais), por estar se referindo a pessoas do mesmo gênero, no segundo, por se referir a uma pessoa do gênero oposto, surge a possibilidade de um novo significado, que faz com que Ingrid tenha a necessidade da confirmação. Foi o fato de já ter vivenciado o diálogo do dia anterior, em que 'gostar' também se referia a envolvimentos afetivos-sexuais ou paqueras, que o diálogo do segundo dia chamou a atenção, no qual 'gostar' entre duas meninas era apenas amizade.

Tamanha é a sutileza (e naturalidade) da norma, que é apenas através da comparação entre os dois trechos que a construção da heterossexualidade pressuposta é evidenciada, por meio da diferença de significados atribuídos ao verbo 'gostar'. Quando utilizado para referir-se ao gênero oposto, o verbo automaticamente tem seu significado associado também à heterossexualidade. Percebe-se que as duas meninas já conhecem a norma heterossexual que constrói a heterossexualidade como pressuposta, tanto Ingrid que a verbalizou na sua confirmação 'Como amigo, né!?'; quanto Fabiana, que no primeiro trecho me falava com espontaneidade das meninas que gostava e não gostava, mas no segundo diálogo o fez em segredo, quando foi referir-se a um menino.

Os significados não estão prontos e acabados na linguagem para serem apreendidos por nós, os significados são móveis e contextuais e são reconstituídos a todo o momento. Dessa forma, estamos comparando entre si significados provenientes das mesmas interlocutoras em situações semelhantes e utilizando a participação de quem pesquisa, como pessoa inserida naqueles eventos e momentos para discorrermos sobre estes. Porém, isso não garante a fixidez dos significados daqueles momentos em que foram pronunciados, e tampouco que esses mesmos significados se repetirão da mesma forma. O que procuramos é captar uma das formas com que esses significados apareceram e fizeram emergir a norma na condição de efeito destes.

Invertendo a cronologia dos acontecimentos na escrita, pretendemos explicitar que a apreensão da norma é um processo e que não se faz a partir de fatos isolados, porque a própria norma se constrói em processo. Esta necessita de constante repetição para sua materialização e perpetuação, e isso acaba por caracterizar tanto sua constituição quanto sua instabilidade, instaurando assim a possibilidade de transgressão, sendo

[...] em virtude dessa reiteração que fossos e fissuras são abertos, fossos e fissuras que podem ser vistos como as instabilidades constitutivas dessas construções, como aquilo que escapa ou excede a norma, como aquilo que não pode ser totalmente definido ou fixado pelo trabalho repetitivo daquela norma. Esta instabilidade é a possibilidade desconstitutiva no próprio processo de repetição, o poder que desfaz os próprios efeitos pelos quais o 'sexo' é estabilizado, a possibilidade de colocar a consolidação das normas 
do 'sexo' em uma crise potencialmente produtiva. (Butler, 2000, p. 163-164)

Ou seja, uma norma institui o mesmo, mas nunca o idêntico (Rodrigues, 2012). Assim, a norma é constituída na cultura e reiterada em práticas cotidianas por meio de pedagogias culturais, o que nunca se dá nas mesmas circunstâncias que possibilitaram as condições para o surgimento da norma. Portanto, a norma não pode ser analisada à parte às suas condições de possibilidades e seus efeitos, pois estes são imanentes à norma, já que a norma não existe em si, mas em atuação. Ela está relacionada a um processo nunca acabado e reiterado todos os dias por interpelações diversas. Somente a partir do primeiro trecho não é possível notar a atuação da norma heterossexual. Se o diálogo do primeiro dia não tivesse acontecido, o verbo 'gostar' entre duas meninas estar somente relacionado à amizade não soaria como relevante na apreensão da norma. Foi então pela diferença de significados atribuídos ao verbo que percebemos a pressuposição de heterossexualidade embutida nas duas situações. Se o fato de uma menina 'gostar' de um menino necessita da confirmação de amizade, então a heterossexualidade está instaurada, o que causa até mesmo certa excitação entre elas, um segredo, pode ser uma paquera. Já quando uma menina 'gosta' de outra menina, isso se revela 'apenas' como sinal de amizade. A rede de relações poder-saber que compõe a heteronormatividade produz a pressuposição de heterossexualidade, ao mesmo tempo em que esta se torna uma das formas de reiterá-la. Essa pressuposição não envolve o rechaço a formas não-heterossexuais de se viver a sexualidade, mas é um processo sutil de reinstauração da própria norma. 


\section{Provocando a norma}

[Everton tem 09 anos e está no $3^{\circ}$ ano do ensino fundamental. Eu já havia conversado com ele algumas vezes. Neste dia, durante o intervalo, estava sentada ao seu lado em um banco em frente à quadra, onde algumas pessoas jogavam vôlei em uma rodinha].

Estamos conversando e Everton me pergunta:

- Sabe de quem eu gosto?

- De quem?

- Adivinha!

- Posso pedir dicas?

- Pode.

- Está aí na quadra?

- Está

- É menino ou menina?

Everton, que até então olhava fixamente para a quadra, dirige o olhar pra mim com uma expressão de surpresa e me responde enérgico, firme, porém não enraivecido:

- Guria, eu não sou gay.

- Uhm, então é menina. - Respondi com naturalidade, sem demonstrar preocupação com o tom da sua resposta - Qual é a cor da camiseta dela?

- É preta.

Continuamos brincando até que eu acertei. Então ele me confidencia:

- Quando vou dormir penso nela.

E me conta rapidamente do dia em que ela deu um beijo nele. Em seguida emenda:

- E adivinha de quem eu não gosto.

- Menino ou menina?

- Dos dois.

Como no momento só havia dois meninos na quadra, eu escolhi um e depois escolhi o outro, mas para minha surpresa não era nenhum dos dois. Então acertei na próxima:

- É a menina de camiseta cinza?

- É. Não gosto dela porque ela corria atrás de mim.

- Corria pra quê?

- Pra me pegar, me bater.

Cena produzida a partir de trecho do diário de campo 
Nessa cena, pelo contexto da conversa, era nítido que Everton se referia ao aspecto da paquera e não ao da amizade quando ele pergunta "Sabe de quem eu gosto?". E, por isso mesmo, dada a situação, Ihe foi perguntado "É menino ou menina?", como modo de provocar a norma, fazê-la falar. O vínculo já estabelecido com Everton desde outras ocasiões permitiu acreditar que a pergunta não comprometeria o diálogo, então se correu o risco. Arriscar, pois ainda assim se contava com a possibilidade de ele sair bravo, ofendido, de não querer mais falar por conta da desconfiança de sua heterossexualidade. Mas não foi o que aconteceu, ele apenas se espantou. $O$ espanto de Everton com a pergunta demonstra a pouca ou nula frequência desse teor de questionamento nesse tipo de situação, o que também está relacionado à corrente pressuposição de heterossexualidade.

As prescrições normativas sobre a sexualidade têm algumas constâncias culturais, e uma delas é que a homossexualidade não é considerada desejável, sendo a heterossexualidade seu contraponto, a norma estabelecida como comportamento ideal. Porém, há certa flexibilidade da norma de acordo com cada contexto. Nesse caso, o comportamento ideal está mantido, mas a norma bambeia para estabelecer seus limiares. Haver espaço para essa pergunta em nosso diálogo nos faz levantar algumas hipóteses: que a homossexualidade pode não ser considerada tão abjeta quanto poderíamos pensar; que podem estar ocorrendo mudanças nos padrões de masculinidade heterossexual, que não mais precisa recusar agressivamente a homossexualidade para se afirmar, e que a valorização das diversidades pode estar fazendo com que a homossexualidade se torne uma possibilidade legitimada socialmente, embora ainda não seja desejável.

Aqui estamos apoiados também em Deleuze (2000) para mostrar que os aprendizados são efeitos dos encontros, dos afetos, e é através deles que a repetição ganha condição de criatividade, e origina nova forma de perceber-se no mundo. Consideramos que esta pergunta realizada durante a conversa com Everton carrega uma dimensão política, pois suspende a pressuposição de heterossexualidade e institui outra possibilidade, a possibilidade de um menino gostar de outro menino. A postura de Everton, permitindo o desenrolar do diálogo, nos encoraja para forçar cotidianamente a norma e, aos poucos, minar a heterossexualidade pressuposta. Para Foucault, a resistência é a possibilidade de criação, de mudança inerente às relações de poder. Não se trata simplesmente de dizer 'não', pois a negação é a forma mínima de resistência, e nem se trata apenas de enfatizar a afirmação para a conquista de espaço. Se voltarmos ao tema da garantia de direitos, mencionada no início do texto, a afirmação identitária é necessária para que o sujeito possa ter o direito à sua sexualidade, mas, segundo o autor, esse problema não pode ser dado como resolvido apenas com isso, e um passo adiante seria

[...] a criação de novas formas de vida, de relações, de amizades nas sociedades, a arte, a cultura de novas formas que se instaurassem por meio de nossas escolhas sexuais, éticas 
e políticas. Devemos não somente nos defender, mas também nos afirmar, e nos afirmar não somente enquanto identidades, mas enquanto força criativa. (Foucault, 2004, p. 262)

Nesse sentido, sublinhamos que a pergunta feita a Everton, "É menino ou menina?", abre caminho para mudanças, mas ainda leva consigo pelo menos dois outros pressupostos que enrijecem as possibilidades de criação: o de que as escolhas afetivosexuais se fazem por discriminação de gênero e de que essas escolhas são divididas em possibilidades binárias de gênero.

\section{Aprender (e ensinar) é resistir diariamente à repetição sem novidade}

Vimos a constituição da heteronormatividade a partir da interação com as interlocutoras do $2^{\circ}$ ano. Elas mostraram que a heterossexualidade está presente nos mais sutis pressupostos e é constituída através da própria afirmação da heterossexualidade. Assim, aprendemos com elas que a heteronormatividade não é constituída somente a partir da negação de outras sexualidades. A cena que protagonizaram Ingrid e Fabiana passa longe de ser uma cena em que é possível detectar o preconceito contra a homossexualidade. Não há abjeção em relação a diferentes formas de se viver a sexualidade, nem repulsa a homossexualidade, o que há é a afirmação da heterossexualidade. Aqui, aquela ideia de que seria possível povoar os espaços sociais com a diversidade, até que a heterossexualidade se tornasse apenas mais uma delas, ficou cada vez mais distante de se confirmar. O que for mostrado sobre diversidade provavelmente não afetará as concepções de Ingrid e Fabiana, pois, nesse caso, a heteronormatividade não está se fazendo pela recusa das diversidades, ela está se fazendo a partir de mecanismos que normalizam as condutas e instituem a heterossexualidade. Elas nos ensinaram que não basta que as diferentes sexualidades se afirmem para trincar a heteronormatividade, pois a todo o momento a heterossexualidade também é reafirmada em sua posição, e por mecanismos bastante sutis.

Mesmo que nem toda manifestação de heteronormatividade implique no reforço do preconceito às sexualidades não-heterossexuais ou em sua recusa explícita, também não permite que estas se constituam como prioritárias. Da instituição da heterossexualidade está implícita a recusa tácita de outras sexualidades. É o que se procurou sacudir na conversa com Everton. Essa cena mostrou que ser gay não é compreendido como uma impossibilidade, mas também não é uma possibilidade $a$ priori. Quando Everton foi questionado sobre se a pessoa que ele gosta é menino ou menina, isso não estremeceu o vínculo com ele e nem esfriou a conversa. Everton não achou que estava sendo insultado por se trazer a possibilidade de homossexualidade para as escolhas afetivas. Assim, ser gay pode não ser mais uma impossibilidade, 
porém, está tacitamente recusado pela repetição sem diferença. E é por isso que Everton ficou surpreso com a pergunta. Ele surpreendeu-se com a insubmissão à recusa tácita da homossexualidade. Talvez resida aí uma potencialidade do trabalho com as diversidades nestes nossos tempos: explorar e minar os caminhos pelos quais essa recusa tácita é construída e reiterada.

Assim, a discussão sobre a norma em sexualidade e gênero não se restringe ao olhar para as identidades não-hegemônicas, em que prevalecem os mecanismos de afirmação identitária e luta contra preconceito, inclusive porque a garantia de direitos funcionando pela identidade acaba por acomodar padrões heteronormativos. O olhar para a norma exige minuciosidade, visto que esta atua por mecanismos sutis. Assim, as manifestações de sexualidade e gênero na escola vão para muito além do que é o formal em sala de aula, pois por meio das pedagogias da sexualidade e de gênero a norma atua no dispositivo da sexualidade nas mais diversas situações, surgindo nos encontros e trocas cotidianas. Muitas vezes, essas pedagogias atuam de modo que as relações de gênero e sexualidade se entrelacem a partir de representações lineares e dicotômicas, atuando na composição da heteronormatividade. Mas também esse arranjo pode ser tensionado pelo inesperado, em que a criação rompe com a repetição. O olhar para a norma alarga as possibilidades de trincá-la, aumentando a viabilidade de outras manifestações de sexualidade e gênero.

Certamente a figura da/o professor/a, como adulto de referência e também como alguém que tem expertise no conhecimento científico, é fundamental neste processo. Ao contrário do que muito se diz hoje em dia, interromper a naturalidade da enunciação da norma não configura atitude de 'fazer a cabeça' das e dos jovens, e muito menos se configura como doutrinação ou abuso de autoridade docente sobre as e os discentes. Essa é a tarefa precípua de um processo educacional, em particular quando ele acontece na escola pública, laica e republicana. Essa é a educação que desejamos, e que pode formar sujeitos que se indaguem sobre a norma, tendo condições de produzir, com liberdade, os modos como vão repetir com diferença.

\section{Referências bibliográficas}

ANDRÉ, Marli Eliza D. A. de. Etnografia da Prática Escolar. Campinas: Papirus, 1995.

BUTLER, Judith. Corpos que pesam: sobre os limites discursivos do 'sexo'. In: LOURO, Guacira Lopes (org). O Corpo Educado: pedagogias da sexualidade. 2. ed. Belo Horizonte: Autêntica, 2000. p. 151-172. 
BUTLER, Judith. Problemas de Gênero. Rio de Janeiro: Civilização Brasileira, 2003.

COSTA, Marisa Vorraber. Apresentação. In: . Caminhos Investigativos: novos olhares na pesquisa em educação. Rio de Janeiro: DP\&A, 2002. p. 9-12.

DELEUZE, Gilles. Diferença e Repetição. Lisboa: Relógio d'Água, 2000.

EWALD, François. Foucault, a Norma e o Direito. Alpiarça (Portugal): Vega, 2000.

FISCHER, Rosa Maria Bueno. "Foucault revoluciona a pesquisa em educação?" Perspectiva, Florianópolis, UFSC, v. 21, n. 02, p. 371-389, jul.-dez. 2003. Disponível em: <http://www.perspectiva.ufsc.br/perspectiva_2003_02/07_artigo_rosa_ maria.pdf >. Acesso em: 31 jan. 2017.

FOUCAULT, Michel. História da Sexualidade I: a vontade de saber. 13. ed. Rio de Janeiro: Graal, 1999.

FOUCAULT, Michel. Michel Foucault, uma entrevista: sexo, poder e a política da identidade. Verve, São Paulo, PUC-SP, n. 05, p. 260-277, 2004. Disponível em: <http://revistas.pucsp.br/index.php/verve/article/viewFile/4995/3537>. Acesso em: 31 jan. 2017.

GAGNON, John. Uma Interpretação do Desejo - ensaios sobre o estudo da sexualidade. Rio de Janeiro: Garamond, 2006.

LOURO, Guacira Lopes. Pedagogias da sexualidade. In:_-_. O Corpo Educado: pedagogias da sexualidade. 2. ed. Belo Horizonte: Autêntica, 2000. p. 9-34.

LOURO, Guacira Lopes. "Teoria queer: uma política pós-identitária para a 
educação". Estudos Feministas, Florianópolis, UFSC, v. 9, n. 2, p. 541-553, 2001. Disponível em: <http://www.scielo.br/pdf/ref/v9n2/8639.pdf_>. Acesso em: 31 jan. 2017.

LOURO, Guacira Lopes. Heteronormatividade e homofobia. In: JUNQUEIRA, Rogério Diniz (Org.). Diversidade Sexual na Educação. Brasília: Ministério da Educação, Secretaria de Educação Continuada, Alfabetização e Diversidade, UNESCO, 2009. p. 85-93.

MISKOLCI, Richard. A teoria queer e a sociologia: o desafio de uma analítica da normalização". Sociologias, Porto Alegre, UFRGS, ano 11, n. 21, p. 150-182, jan.jun. 2009. Disponível em: <http://www.scielo.br/pdf/soc/n21/08.pdf_>. Acesso em: 31 jan. 2017.

PICCHETTI, Yara de Paula; SEFFNER, Fernando. Cada um com a sua certeza: a escola e os esforços cotidianos para estar na norma e resistir a esta. In.: SILVA, I. Ri. da; NEVES, A. L. M. Das; SILVA, F. P. P. da. (orgs.) Educação e Sexualidade: uma perspectiva crítica. Manaus, Universidade Federal do Amazonas UFAM: UEA Edições, 2016, v.1, p. 79-100.

$\mathrm{RICH}$, Adrienne. Heterossexualidade compulsória e existência lésbica. Bagoas, Natal, UFRN, n. 5, p. 17-44, 2010. Disponível em: <http://www.cchla.ufrn.br/ bagoas/v04n05art01_rich.pdf_>. Acesso em: 31 jan. 2017.

RODRIGUES, Carla. Performance, gênero, linguagem, alteridade: J.Butler e J.Derrida. Sexualidad, Salud, y Sociedad, Revista Latinoamericana, n. 10, p. 140164, abr. 2012. Disponível em: <http://www.scielo.br/pdf/sess/n10/a07n10.pdf >. Acesso em: 31 jan. 2017.

RUBIN, Gayle. O Tráfico de Mulheres: notas sobre a "economia política" do sexo. Recife: SOS Corpo, 1993. 
SEDGWICK, Eve Kosofsky. A epistemologia do armário. Cadernos Pagu, Campinas, UNICAMP, v. 28, p. 19-54, jan.-jun. 2007. Disponível em: <http://www.scielo.br/ pdf/cpa/n28/03.pdf_>. Acesso em: 31 jan. 2017.

SEFFNER, Fernando. Modus vivendi, liberdade religiosa e liberdade sexual: o que a escola tem a ver com isso? In: NARDI, H. C.; MACHADO, P. S.; SILVEIRA, R. da S. (Orgs.). Diversidade sexual e relações de gênero nas políticas públicas: o que a laicidade tem a ver com isso? Porto Alegre: Editora Deriva/ABRAPSO, 2015, p. 81-104.

SEFFNER, Fernando; PICCHETTI, Yara de Paula. A escola pública brasileira e seu compromisso com a diversidade de gênero e sexualidade. In: MAGALHÃES, J. C.; RIBEIRO, P. R. C. (Orgs.). Educação para a sexualidade. Rio Grande: Editora da FURG, 2014, p. 67-81.

WARNER, Michael. Fear of a queer planet. Minneapolis: University of Minnesota, 1993. 
Yara de Paula Picchetti Possui graduação em Psicologia pelo Instituto de Psicologia da Universidade de São Paulo(2009), graduação em Licenciatura em Psicologia pela Faculdade de Educação da Universidade de São Paulo(2010), graduação em Bacharel em Psicologia pelo Instituto de Psicologia da Universidade de São Paulo(2009), mestrado em Educação pela Universidade Federal do Rio Grande do Sul(2014) e aperfeicoamento em Orientação à Queixa Escolar pelo Instituto de Psicologia da Universidade de São Paulo(2011). Atualmente é Orientadora Educacional do Colégio Luterano Arthur Konrath. Tem experiência na área de Educação

Fernando Seffner Graduado em Geologia e em História pela Universidade Federal do Rio Grande do Sul (UFRGS), Mestrado em Sociologia e Doutorado no Programa de Pós-Graduação em Educação UFRGS (2003). Professor Associado IV da Faculdade de Educação da UFRGS Departamento de Ensino e Currículo. Docente e orientador junto ao Programa de Pós-Graduação em Educação (PPGEDU) na linha de pesquisa Educação, Sexualidade e Relações de Gênero, com ênfase temática nas pedagogias de construção das masculinidades. Docente e orientador no Mestrado Profissional em Ensino de História - PROFHISTÓRIA, polo UFRGS. Atua em pesquisas e orientações investigando situações de vulnerabilidade a AIDS; conexões entre direitos humanos e políticas públicas de gênero e sexualidade, teorizações queer, interseccionalidade $e$ marcadores da diferença. No nível de graduação dedica-se a disciplinas que envolvem o ensino de História e pesquisa as conexões entre experiência e aprendizagem da História a partir da etnografia de cenas de sala de aula. É líder do Grupo de Estudos em Educação e Relações de Gênero GEERGE PPGEDU UFRGS e integrante da equipe do LISTHE Laboratório de Ensino de História e Educação FACED IFCH CAP UFRGS e do Núcleo de Estudos e Pesquisas em AIDS NEPAIDS USP, todos registrados no DGP CNPQ. Coordenador do GT23 - Gênero, Sexualidade e Educação da ANPED Associação Nacional de Pós-Graduação e Pesquisa em Educação (2017-2021). É Bolsista de Produtividade em Pesquisa do CNPq - Nível 2 - CA ED - Educação 